\title{
Women's Sexual Empowerment and Contraceptive Use in Ghana
}

\author{
Halley P. Crissman, Richard M. Adanu, and Siobán D. Harlow
}

\begin{abstract}
Pervasive gendered inequities and norms regarding the subordination of women give Ghanaian men disproportionately more power than women, particularly in relation to sex. We hypothesize that lack of sexual empowerment may pose an important barrier to reproductive health and adoption of family planning methods. Using the 2008 Ghana Demographic Health Survey, we examine the association between women's sexual empowerment and contraceptive use in Ghana among nonpregnant married and partnered women not desiring to conceive in the next three months. Increasing levels of sexual empowerment are found to be associated with use of contraceptives, even after adjusting for demographic predictors of contraceptive use. This association is moderated by wealth. Formal education, increasing wealth, and being in an unmarried partnership are associated with contraceptive use, whereas women who identify as being Muslim are less likely to use contraceptives than those who identify as being Christian. These findings suggest that to achieve universal access to reproductive health services, gendered disparities in sexual empowerment, particularly among economically disadvantaged women, need to be better addressed (STUDIES IN FAMILY PlanNIng 2012; 43[3]: 201-212)
\end{abstract}

The revised framework for global family planning that emerged from the 1994 International Conference on Population and Development (ICPD) in Cairo marked a shift in focus away from population control and toward emphasizing women's reproductive and sexual rights and empowerment (Blanc and Tsui 2005). The global importance of reproductive and sexual empowerment stems partly from the recognition across cultures that intimate relationships frequently occur between individuals who have vastly unequal power (Dixon-Mueller 1993; Amaro 1995; Pulerwitz, Gortmaker and DeJong 2000; Blanc 2001; Pearson 2006). In most cultures, normative expectations regarding gendered heterosexual sex roles and socially ingrained gender inequities negatively affect women's relative sexual power and limit women's ability to engage in sexual negotiation with male partners (Blanc 2001; Pearson 2006). As the family planning community moves forward with the 1994 ICPD paradigm and strives

Halley P. Crissman is a medical student, University of Michigan Medical School, Richard M. Adanu is Associate Professor, School of Public Health, University of Ghana, and Siobán D. Harlow is Professor of Epidemiology, School of Public Health, University of Michigan. Address correspondence to Halley P. Crissman, 1301 Catherine Road, Ann Arbor, Michigan 48109. E-mail: hcrissma@umich.edu. to achieve universal access to reproductive health services by 2015- a target added to Millennium Development Goal 5 at the 2005 United Nations World Summit-the role of women's empowerment in sexual and reproductive health warrants further investigation.

Many family planning initiatives focus on improving access to and knowledge of contraceptives and safe sex. These approaches are beneficial, although they are not necessarily sufficient to increase women's control over their sexual and reproductive health (Malhotra and Mehra 1999). We hypothesize that for some women, a lack of sexual empowerment may pose a significant barrier to achieving sexual and reproductive health. For example, a woman with access to and knowledge of contraceptives may feel unable to use them if she does not see reproductive and sexual health and autonomy as her right. Although general empowerment, relative power in relationships, sexual self-efficacy, and control over fertility have been explored separately elsewhere, we found no studies that evaluate women's empowerment specifically in relation to sexual contexts.

Malhotra, Schuler, and Boender (2002) define women's empowerment as a process of increasing agency over time. Empowerment has also been conceptualized as one's perceptions of his/her relative skills, rights, and options (Gutiérrez, Oh, and Gillmore 2000). Education and employment have both been used as prox- 
ies for women's empowerment, and in turn have been associated with fertility regulation (Mason 1984). More recently, scales designed to measure women's relative power in intimate relationships have been developed. The widely recognized Sexual Relationship Power Scale (SRPS) attempts to capture women's subjective experience of power in intimate relationships using subscales of general relationship control and decisionmaking dominance (Pulerwitz, Gortmaker, and DeJong 2000). The SRPS acknowledges that power resides in relationships and within a larger social context; however, evidence of the association between the general power dynamics in an intimate partnership and contraceptive practice has been inconsistent, leading some to hypothesize that general relationship power may not accurately reflect partners' empowerment in sexual contexts (Cabral et al. 1997; Pulerwitz, Gortmaker, and DeJong 2000; Soler et al. 2000; Harvey et al. 2002; Pulerwitz et al. 2002; Pettifor et al. 2004; Teitelman et al. 2008; Wang and Chiou 2008).

Given the multidimensional nature of empowerment (economic, interpersonal, political, sexual, sociocultural, and so on), a woman may be empowered in one sphere of her life but not in others (Gutiérrez, Oh, and Gillmore 2000; Pulerwitz, Gortmaker, and DeJong 2000; Williams 2005; Lee-Rife 2010). Thus, disentangling the association between empowerment and sexual and reproductive health requires specificity in the conceptualization of empowerment. This approach, previously adopted by studies of economic empowerment and its relationship to women's control of their sexual and reproductive health, set the foundation for the integration of microfinance into some HIV-prevention programs (Gage 1995; SwartKruger and Richter 1997; Grieg and Koopman 2003; Kim et al. 2008).

Constructs of self-efficacy, a concept similar to empowerment, have been explored in sexual contexts, particularly in relation to HIV-prevention interventions (Bandura 1990; Rosenthal, Moore, and Flynn 1991; Bowleg, Belgrave, and Reisen 2000). Studies of the association between women's sexual self-efficacy and general contraceptive use have largely found the association to be positive, whereas evidence regarding the relationship between women's sexual self-efficacy and male condom use has been less consistent, likely as a result of the partner cooperation that condom use requires (Levinson 1986; Bandura 1990; Basen-Engquist 1992; Cochran and Mays 1993; Heinrich 1993; Sikkema et al. 1995; Sionéan and Zimmerman 1999; Bowleg, Belgrave, and Reisen 2000; Gutiérrez, Oh, and Gillmore 2000; Blanc and Wolff 2001).

Self-efficacy is one's perceived ability to perform a behavior and obtain a particular result, whereas empowerment is focused less on outcome expectation and more on one's beliefs regarding one's skills, rights, and options (Gutiérrez, Oh, and Gillmore 2000). Women's perception of their sexual and reproductive health skills, rights, and options may be as important to their sexual and reproductive health as their perceived ability to achieve a particular health outcome in sexual contexts. This study assesses women's sexual empowerment and its association with contraceptive use in Ghana.

We hypothesize that cultural norms, including normative gender roles, which classically subordinate women, shape contraceptive practices through their influence on women's sexual empowerment. In this study, we measure women's empowerment in sexual spheres-both perceived rights and options - to explore the potential importance of empowerment in sexual partnerships and to consolidate aspects of sexual empowerment previously nested in related constructs. A woman's sexual empowerment is conceptualized as her perception of the right to self-determination in sexual relations and her ability to express herself in sexual decisionmaking. We present results of a cross-sectional analysis of the association between women's sexual empowerment and contraceptive use in Ghana, a country with widespread gendered power inequities (Bawah et al. 1999; GSS 2009). We hypothesize that women's sexual empowerment will be positively associated with contraceptive use, which, if true, would suggest that interventions aimed at increasing contraceptive use in heterosexual partnerships would benefit from addressing women's sexual empowerment.

\section{Setting}

In Ghana, family planning is promoted by the Ministry of Health and organizations such as Planned Parenthood Association of Ghana, but prevalence of contraceptive use remains low. In 2008, only 24 percent of married women were practicing contraception (Adanu et al. 2009; GSS 2009). The use of male condoms is limited in Ghana, with 18 percent of unmarried sexually active women and just 2 percent of married women citing male condoms as their most common means of contraception (GSS 2009). Although Ghana's total fertility rate of 4.0 births per woman is one of the lowest in sub-Saharan Africa, in 2008 only 40 percent of women's family planning needs were being met (a 3 percent increase in unmet need compared with 2003) (GSS 2009).

Consistent with many studies of contraceptive use, formal education has been shown to be strongly associated with contraceptive use in Ghana (Cochran 1979; Njogu 1991; Gage 1995; Addai 2000; Adanu et al. 2009). Addai (2000) found that Ghanaian women who were unemployed (compared with manual laborers) or had no living 
children (compared with those with children) were less likely to practice contraception. Ghanaian women's unmet need for family planning may be partially explained by the apparent conflict between modern contraceptive techniques and traditional social organization, ingrained gendered power dynamics, beliefs regarding women's reproductive obligations, and the social desirability of children (Adongo et al. 1997; Bawah et al. 1999; Bawah 2002). Contraceptive use in Ghana may also be hindered by the association of condoms with infidelity and disease, and contraceptives in general with promiscuity, as well as issues regarding access, cost, and education (Blanc 2001). In developing countries like Ghana, demographic factors such as high socioeconomic status, urban residence, and easy access to family planning services have been positively associated with contraceptive use, whereas religious and social restrictions have been identified as barriers (Anate 1995; Khan 1996; Kannae and Pendleton 1998; Orji and Onwudiegwu 2002; Adanu et al. 2009). Notably, the distribution of many of these factors, including economic empowerment, social restrictions, and access to education and employment, are skewed in favor of men, whereas responsibility for obtaining contraceptives often falls to women.

\section{Data and Methods}

Data for this study were drawn from the 2008 Ghana Demographic and Health Survey (DHS), a nationally representative cross-sectional study of the population and health of Ghanaians. The methodology has been described in detail elsewhere (GSS 2009). Briefly, the 2008 Ghana DHS employed a complex sample design involving systematic selection of 412 geographic clusters within the country's ten regions, and subsequent random selection of 30 households within each cluster. In a randomly selected half of the 11,778 households surveyed, women aged 15-49 were asked to complete the 2008 Ghana DHS Women's Questionnaire (Version 5), which inquired about background, reproductive behavior, contraceptive practices, antenatal and delivery care, and status. Out of 5,094 eligible women, 4,916 (97 percent) completed the questionnaire. Data were collected between September and November 2008.

All women who completed the DHS Women's Questionnaire and who self-identified as being married or having a live-in partner, as not being pregnant at the time of the interview, and as not wanting to become pregnant "soon" or within the next three months were eligible for inclusion in the present analysis $(\mathrm{n}=2,129)$. Nonpartnered women were excluded from this study to standardize the target population's use of contraceptives and sexual empowerment in the context of established sexual relationships. Women with missing data on any of the key analysis variables were excluded $(n=25)$, resulting in an analytic sample of 2,104.

Data management and recoding were conducted using both SAS version 9.2 software and STATA/SE version 11.1 software. All data analysis was conducted using STATA/SE version 11.1 software. P-values less than or equal to 0.05 were considered statistically significant.

\section{Variables}

\section{Current Contraceptive Use}

Women who stated that they were using modern contraceptive methods (condom, diaphragm, female or male sterilization, foam/jelly, implant, injectables, intrauterine device, lactational amenorrhea, oral contraceptives) $(\mathrm{n}=436)$, traditional methods (abstinence, periodic abstinence, withdrawal) $(n=137)$, or folk methods (other methods) ( $\mathrm{n}=16)$ were categorized as "currently using contraceptives" $(n=589)$. Those who did not identify as using any method of contraception were categorized as "not currently using contraceptives" $(\mathrm{n}=1,515)$.

\section{Sexual Empowerment}

To explore women's sexual empowerment, a crude composite score was created to capture participants' perceptions of their right to self-determination and equity in sexual relations, and their ability to express themselves in sexual decisionmaking. Women's sum on five dichotomous items was used as their sexual empowerment score $(0=$ least sexually empowered; $5=$ most sexually empowered). The five items were:

- Can you say "no" to your husband/partner if you do not want to have sexual intercourse?

- In your opinion, is a husband justified in hitting or beating his wife if she refuses to have sex with him?

- Could you ask your husband/partner to use a condom if you wanted him to?

- If a wife knows her husband has a disease that she can contract during sexual intercourse, is she justified in asking him to use a condom when they have sex?

- Is a woman justified in refusing sex if she is tired/not in the mood?

The average correlation of the five binary items was calculated using the Kuder-Richardson Formula 20 method to assess scale reliability. In addition to exploring the association between individual-level sexual empowerment and contraceptive use, mean sexual empowerment in each region was calculated and converted into a con- 
tinuous regional-level variable to examine the association between women's sexual empowerment in each region and the contraceptive use of women within that region.

\section{Covariates}

Participants' age, educational status, religion, marital status, region of residence, urban/rural status, household size, number of living children, wealth index, and employment status were examined as potential confounders. Women were categorized into one of three self-reported age groups: 15-24, 25-34, and 35-49 years. Initial data analysis revealed little difference in the odds of contraceptive use among those with varying levels of education. Thus, education was dichotomized as "no formal education" and "some formal education." Religion was categorized as Christian, Muslim, or other; the latter category included individuals identifying as "traditional spiritualist" or having no religion. Marital status was categorized as married or "partnered" (coded as "living together" in the DHS).

Region of residence was based on location of the household within Ghana's ten nationally recognized regions (Ashanti, Brong Ahafo, Central, Eastern, Great Accra, Northern, Upper East, Upper West, Volta, and Western). Given the large number of categories in the "region" variable and the limited number of participants per region, combined region variables were also analyzed to preserve statistical power. The Northern, Upper East, and Upper West regions were categorized as North, given their similar geographic remoteness and subsequent ethnic and cultural differences from the South; all other regions were categorized as South. Similarly, setting of residence (urban/rural) was based on the household location and categorization by the Ghana DHS. Household size was represented in quintiles (smallest to largest, calculated prior to invoking exclusion criteria) $(n=4,916)$, based on the number of household members (the usual number of residents plus those who slept in the house the night before). The number of living children reported was coded as either $0,1,2,3-4$, or 5 or more. Wealth index was a composite measure of the cumulative living standard of participants, measured by the household's ownership of selected assets such as a television, bicycle, source of water access, and sanitation facility. Wealth-index scores were standardized in relation to a normal distribution and divided into quintiles by the DHS. Employment status was determined based on participants' self-reported work status, wherein being employed included but was not limited to skilled and unskilled labor, agricultural work, and employment in sales and the service industry. Age, household size, wealth, and number of children were considered both as ordinal and nominal categorical variables. In the final model, age was included as a nominal variable, whereas household size, wealth, and number of living children were included as ordinal variables.

\section{Statistical Analysis}

A design-based analysis (as opposed to a model-based analysis) approach was used to account for the nonrandom sampling design of the DHS. Specialized procedures for design-based analyses in STATA version 11.1, such as weighting and clustering, were used to ensure that the analyses appropriately accounted for the complex survey sample. The term "target population" refers to the population represented by estimates generated after accounting for the complex sample design and exclusion criteria. All results are estimates for the target population unless otherwise stated. Simple design-based bivariate associations of all covariates with current contraceptive use were examined using Rao-Scott F-tests. Design-based logistic regression models of the odds of current contraceptive use were then used to estimate crude odds ratios. To account for design effects, pseudo-maximum likelihood estimation was used to compute weighted estimates of logistic regression coefficients, and Binder's Taylor series linearization approach was used to estimate the variances of the estimated logistic regression coefficients (Binder 1983; Heeringa, West, and Berglund 2010). Additionally, design-based linear regression models were fitted to examine bivariate associations between covariates and sexual empowerment. The five individual components of the sexual empowerment score and the overall sexual empowerment composite score were also included in the logistic regression models to examine the association with current contraceptive use. All covariates were included in the multivariate model. Potential interactions between women's sexual empowerment and each covariate were also assessed, and observed interactions were included in a second multivariate model. An additional model was constructed to include women's mean sexual empowerment by region as a covariate. Estimates of logistic regression coefficients were converted to odds ratios by raising base $e$ to the power of the logistic regression coefficients (Hosmer and Lemeshow 2000).

\section{Results}

The median age of the target population was 34 years. As shown in Table 1, most had some formal education (69 percent), identified as Christian (74 percent), were married (79 percent), lived in an area classified as rural (59 
Table 1 Percentage of weighted target population, odds ratio of current contraceptive use, and sexual empowerment score, by selected demographic variables $(\mathrm{N}=2,104)$, Ghana, 2008

\begin{tabular}{|c|c|c|c|c|c|c|}
\hline \multirow[b]{2}{*}{ Variables } & \multirow{2}{*}{$\begin{array}{r}\text { Weighted } \\
\text { percent }\end{array}$} & \multicolumn{3}{|c|}{ Using contraceptives } & \multicolumn{2}{|c|}{$\begin{array}{l}\text { Sexual empowerment } \\
\text { score }\end{array}$} \\
\hline & & percent & odds & F-test ${ }^{a}$ & Mean & F-test \\
\hline \multicolumn{7}{|l|}{ Age (years) } \\
\hline $15-24(r)$ & 15.5 & 30.4 & 1.00 & \multirow{3}{*}{$\begin{array}{r}F(2.0,787.9)=0.13 \\
p \text {-value }=0.8744\end{array}$} & 4.10 & \multirow{3}{*}{$\begin{aligned} F(9.3,3692.2) & =1.00 \\
p \text {-value } & =0.44\end{aligned}$} \\
\hline $25-34$ & 38.5 & 28.9 & 0.93 & & 4.07 & \\
\hline $35-49$ & 46.0 & 30.0 & 0.98 & & 4.11 & \\
\hline \multicolumn{7}{|l|}{ Education } \\
\hline None $(r)$ & 30.6 & 16.4 & 1.00 & $F(1.0,396.0)=56.80$ & 3.67 & \multirow{2}{*}{$\begin{array}{r}F(4.7,1845.2)=21.36 \\
p \text {-value }<0.0001\end{array}$} \\
\hline Some & 69.4 & 35.5 & $2.81^{\star \star \star}$ & $\mathrm{p}$-value $<0.0001$ & 4.27 & \\
\hline \multicolumn{7}{|l|}{ Religion } \\
\hline Christian (r) & 74.0 & 33.4 & 1.00 & \multirow{3}{*}{$\begin{array}{r}F(2.0,775.1)=14.19 \\
p \text {-value }<0.0001\end{array}$} & 4.24 & \multirow{3}{*}{$\begin{array}{r}F(7.8,3097.5)=9.18 \\
p-\text { value }<0.0001\end{array}$} \\
\hline Muslim & 15.8 & 15.3 & $0.36^{\star \star \star}$ & & 3.71 & \\
\hline Other & 10.2 & 24.6 & 0.65 & & 3.55 & \\
\hline \multicolumn{7}{|l|}{ Marital status } \\
\hline Married (r) & 78.7 & 27.6 & 1.00 & $F(1.0,396.0)=12.40$ & 4.07 & \multirow{2}{*}{$\begin{array}{r}F(4.8,1897.1)=0.62 \\
p \text {-value }=0.68\end{array}$} \\
\hline Partnered & 21.3 & 37.3 & $1.57^{\star \star \star}$ & $p$-value $=0.0005$ & 4.16 & \\
\hline \multicolumn{7}{|l|}{ Region } \\
\hline Ashanti & 18.7 & 35.0 & 0.77 & \multirow{10}{*}{$\begin{array}{r}F(8.4,3321.0)=6.32 \\
p \text {-value }<0.0001\end{array}$} & 3.91 & \multirow{10}{*}{$\begin{array}{r}F(32.6,12907.7)=4.33 \\
\text { p-value }<0.0001\end{array}$} \\
\hline Brong Ahafo & 9.3 & 35.8 & 0.80 & & 4.01 & \\
\hline Central & 9.3 & 27.8 & $0.55^{\star}$ & & 4.46 & \\
\hline Eastern & 9.2 & 30.7 & 0.63 & & 4.34 & \\
\hline Greater Accra (r) & 13.8 & 41.2 & 1.00 & & 4.42 & \\
\hline Northern & 10.6 & 8.2 & $0.13^{\star \star \star}$ & & 3.40 & \\
\hline Upper East & 5.9 & 18.6 & $0.33^{\star \star \star}$ & & 3.68 & \\
\hline Upper West & 3.1 & 20.1 & $0.36^{\mathrm{b}}$ & & 4.02 & \\
\hline Volta & 10.6 & 35.2 & 0.78 & & 4.17 & \\
\hline Western & 9.5 & 24.7 & $0.47^{* *}$ & & 4.39 & \\
\hline \multicolumn{7}{|l|}{ Combined region } \\
\hline North (r) & 19.6 & 13.3 & 1.00 & $F(1.0,396.0)=41.99$ & 3.58 & \multirow{2}{*}{$\begin{array}{r}F(4.2,1656.8)=16.20 \\
p \text {-value }<0.0001\end{array}$} \\
\hline South & 80.4 & 33.6 & $3.32^{\star \star \star}$ & p-value $<0.0001$ & 4.21 & \\
\hline Setting & & & & & & \\
\hline Urban (r) & 41.2 & 34.3 & 1.00 & $F(1.0,396.0)=8.16$ & 4.30 & $F(4.5,1784.9)=8.43$ \\
\hline Rural & 58.8 & 26.4 & $0.69^{* *}$ & $p$-value $=0.005$ & 3.94 & p-value $<0.0001$ \\
\hline Household size & & & & & & \\
\hline Smallest (r) & 6.8 & 35.4 & 1.00 & & 4.35 & \\
\hline Smaller & 31.8 & 29.2 & 0.75 & $F(39-15487)=368$ & 4.18 & $F(17870394)=223$ \\
\hline Middle & 19.4 & 33.6 & 0.92 & $1(0.5,1040.1)-0.00$ & 4.18 & ? \\
\hline Larger & 24.4 & 32.1 & 0.86 & $p$-value $=0.000$ & 4.06 & $p$-value $=0.002$ \\
\hline Largest & 17.6 & 20.6 & $0.47^{* *}$ & & 3.77 & \\
\hline Number of living chi & & & & & & \\
\hline 0 & 2.8 & 51.4 & $2.73^{\star \star \star}$ & & 4.58 & \\
\hline 1 & 13.5 & 27.9 & 1.00 & $F(38.15146)=311$ & 4.25 & $F(178,70348)=215$ \\
\hline 2 & 19.4 & 27.4 & 0.97 & (10.0, Tut & 4.13 & \\
\hline $3-4$ & 37.1 & 31.1 & 1.16 & & 4.12 & \\
\hline $5+(r)$ & 27.2 & 27.9 & 1.00 & & 3.90 & \\
\hline Wealth Index & & & & & & \\
\hline Poorest (r) & 21.1 & 16.5 & 1.00 & & 3.52 & \\
\hline Poorer & 20.4 & 26.4 & $1.82^{\star *}$ & $F(39.15254)=1340$ & 3.98 & $F(17268123)=769$ \\
\hline Middle & 18.5 & 27.7 & $1.95^{\star \star}$ & $1(0.5,1020.4)-10.40$ & 4.20 & ( \\
\hline Richer & 21.2 & 35.7 & $2.82^{\star \star \star}$ & $p$-value < 0.0001 & 4.39 & \\
\hline Richest & 18.7 & 43.1 & $3.84^{\star \star \star}$ & & 4.39 & \\
\hline Employment & & & & & & \\
\hline Unemployed (r) & 8.3 & 25.6 & 1.00 & $F(1.0,396.0)=1.32$ & 3.92 & $F(4.0,1563.8)=3.17$ \\
\hline Employed & 91.7 & 30.0 & 1.25 & $p$-value $=0.25$ & 4.10 & $p$-value $=0.014$ \\
\hline
\end{tabular}

${ }^{*}$ Significant at $\mathrm{p} \leq 0.05 ;{ }^{* *} \mathrm{p} \leq 0.01 ;{ }^{* * *} \mathrm{p} \leq 0.001 . \quad(\mathrm{r})=$ Reference category.

${ }^{a}$ Rao-Scott design-based F-test. ${ }^{b} p$-value $=0.052$

Note: The target population consists of 2,104 married or partnered women who are not pregnant and who do not wish to become pregnant in the next three months. 
percent), had at least three living children (64 percent), and were employed (92 percent). Just 30 percent of women in the target population were estimated to be using contraceptives (not shown).

Educational status, religion, marital status, region, combined region, urban/rural setting, household size, number of living children, and wealth were all significantly associated with contraceptive use, whereas age and employment status were not (Table 1). The crude odds of current contraceptive use was higher among women with some education compared with those with none $(\mathrm{OR}=2.81 ; \mathrm{p}<0.001)$, higher among partnered compared with married women $(\mathrm{OR}=1.57$; $\mathrm{p}=0.001)$, and rose across all wealth quintiles. The crude odds of current contraceptive use was significantly lower among Muslim women compared with Christian women $(\mathrm{OR}=0.36$; $\mathrm{p}<0.001)$, and lower among women living in rural areas compared with urban $(\mathrm{OR}=0.69 ; \mathrm{p}=0.005)$. Compared to women in the Greater Accra area, women in the Western $(O R=0.47 ; p=0.002)$, Central $(O R=0.55 ; p=0.025)$, Northern $(\mathrm{OR}=0.13 ; \mathrm{p}<0.001)$, Upper East $(\mathrm{OR}=0.33$; $\mathrm{p}<0.001)$, and Upper West $(\mathrm{OR}=0.36 ; \mathrm{p}=0.052)$ regions had significantly decreased crude odds of currently using contraceptives. The crude odds of women practicing contraception in the South was $3.32(p<0.001)$ times greater than those of women practicing in the North.

Between 72 and 88 percent of the target population's responses to each of the five items of the sexual empowerment scale were coded as "empowered." The distribution of the composite women's sexual empowerment scores was thus skewed toward empowerment (see Table 2 and Figure 1). The Kuder-Richardson reliability coefficient for the five items in the composite score was 0.54, suggesting that the homogeneity among the five items was not particularly high. Removing single component items from the composite score did not improve it; the highest reliability coefficient recorded was 0.59 . Little evidence of collinearity existed between women's sexual empowerment components (variance inflation factors: 1.01-1.15).

Women who were more sexually empowered had increased odds of contraceptive use (Table 2 and Figure 1). For each one-unit increase in the overall women's sexual empowerment score, the crude odds of current contraceptive use increased by 41 percent $(\mathrm{OR}=1.41 ; \mathrm{p}<0.001)$. Squared and cubed terms for women's sexual empowerment were not found to be statistically significant.

Table 2 Percentage of weighted target population and odds ratio of current contraceptive use, by sexual empowerment variables $(\mathrm{N}=2,104)$, Ghana, 2008

\begin{tabular}{|c|c|c|c|c|}
\hline \multirow[b]{2}{*}{ Sexual empowerment variable } & \multirow[b]{2}{*}{$\begin{array}{r}\text { Weighted } \\
\text { percent }\end{array}$} & \multicolumn{3}{|c|}{ Using contraceptives } \\
\hline & & $\begin{array}{r}\text { Weighted } \\
\text { percent }\end{array}$ & F-test ${ }^{a}$ & $\begin{array}{r}\text { Crude } \\
\text { odds }\end{array}$ \\
\hline \multicolumn{5}{|l|}{ Participant can refuse sex } \\
\hline No $(r)$ & 20.4 & 21.7 & $F(1.0,396.0)=13.5$ & 1.00 \\
\hline Yes & 79.6 & 31.7 & $\mathrm{p}$-value $=.0003$ & $1.68^{\star * *}$ \\
\hline \multicolumn{5}{|c|}{ Participant feels beating is justified if sex is refused } \\
\hline Yes (r) & 15.2 & 22.7 & $F(1.0,396.0)=6.3$ & 1.00 \\
\hline No & 84.8 & 30.9 & $p$-value $=0.0127$ & $1.52^{\star \star}$ \\
\hline \multicolumn{5}{|c|}{ Participant can ask partner to use a condom } \\
\hline No $(r)$ & 27.6 & 19.1 & $F(1.0,396.0)=29.2$ & 1.00 \\
\hline Yes & 72.4 & 33.7 & $\mathrm{p}$-value $<0.0001$ & $2.14^{\star \star \star}$ \\
\hline \multicolumn{5}{|c|}{$\begin{array}{l}\text { Participant feels justified to ask partner to use condom } \\
\text { if he has a sexually transmitted infection }\end{array}$} \\
\hline No $(r)$ & 12.3 & 16.9 & $F(1.0,396.0)=15.92$ & 1.00 \\
\hline Yes & 87.7 & 31.4 & $p$-value $=0.0001$ & $2.25^{\star \star \star}$ \\
\hline \multicolumn{5}{|c|}{$\begin{array}{l}\text { Participant feels a wife is justified in refusing sex } \\
\text { if tired/not in the mood }\end{array}$} \\
\hline No $(r)$ & 15.7 & 23.5 & $F(1.0,396.0)=6.2$ & 1.00 \\
\hline Yes & 84.3 & 30.8 & $p$-value $=0.0130$ & $1.45^{\star \star}$ \\
\hline \multicolumn{5}{|l|}{ Sexual empowerment score } \\
\hline 0 (least empowered) & 1.0 & 7.9 & & \\
\hline 1 & 2.9 & 20.8 & & \\
\hline 2 & 6.3 & 14.0 & $F(4.9,1938.2)=9.9$ & $1.41^{\star \star *}$ \\
\hline 3 & 14.7 & 22.8 & $p$-value $<0.0001$ & \\
\hline 4 & 26.3 & 25.5 & & \\
\hline 5 (most empowered) & 48.8 & 36.9 & & \\
\hline
\end{tabular}


Figure 1 Distribution of weighted respondents by sexual empowerment score and use of contraceptives $(N=2,104)$, Ghana, 2008



Combined region was used instead of region in the multivariate logistic regression models because of the large number of regions and comparatively small sample sizes in selected regions. Women's sexual empowerment score, education, religion, marital status, and wealth remained significant in the full model (Table 3). The adjusted odds of current contraceptive use was 1.73 times higher $(p=0.001)$ among those in the target population who had some education, compared with those with no education, 1.42 times higher $(p=0.010)$ among partnered women, compared with married women, and significantly lower for Muslim women, compared with Christian women $(\mathrm{OR}=0.65 ; \mathrm{p}=0.022)$. For each one-unit increase in wealth quintile, the adjusted odds of current contraceptive use increased 30 percent $(p<0.001)$. In the adjusted model, each one-unit increase in women's sexual empowerment was associated with a 24 percent increase in the odds of current contraceptive use $(\mathrm{p}<0.001)$.

The relationship between women's sexual empowerment and current contraceptive use was moderated by wealth (interaction term $\mathrm{p}$-value $=0.054$; not shown). As wealth rank increased, women's sexual empowerment score was less associated with current contraceptive use (Figure 2).

In a univariate model exploring the association between mean regional women's sexual empowerment and contraceptive use (not shown), a one-unit increase in the average women's sexual empowerment score in a geographic region was associated with women living in that region being 2.57 times more likely to use contraceptives $(p<0.001)$. When average regional sexual empowerment was added to the multivariate model, however, regional sexual empowerment dropped below significance $(\mathrm{OR}=$
Table 3 Odds ratios for multivariate logistic regression models predicting current contraceptive use, by selected characteristics $(\mathrm{N}=2,104)$, Ghana, 2008

\begin{tabular}{|c|c|}
\hline Characteristic & $\begin{array}{l}\text { Adjusted } \\
\text { odds ratio }\end{array}$ \\
\hline Sexual empowerment & $1.24^{\star \star \star}$ \\
\hline \multicolumn{2}{|l|}{ Age (years) } \\
\hline $15-24(r)$ & 1.00 \\
\hline $25-34$ & 0.85 \\
\hline $35-49$ & 0.87 \\
\hline \multicolumn{2}{|l|}{ Education } \\
\hline None & 1.00 \\
\hline Some & $1.73^{* \star *}$ \\
\hline \multicolumn{2}{|l|}{ Religion } \\
\hline Christian & 1.00 \\
\hline Muslim & $.65^{\star}$ \\
\hline Other & 1.32 \\
\hline \multicolumn{2}{|l|}{ Marital status } \\
\hline Married ( $r$ ) & 1.00 \\
\hline Partnered & $1.42^{\star \star}$ \\
\hline \multicolumn{2}{|l|}{ Combined region } \\
\hline North (r) & 1.00 \\
\hline South & 1.37 \\
\hline \multicolumn{2}{|l|}{ Residence } \\
\hline Urban (r) & 1.00 \\
\hline Rural & 1.21 \\
\hline Household size & 1.02 \\
\hline Living children & 1.12 \\
\hline Wealth Index & $1.30^{\star \star *}$ \\
\hline \multicolumn{2}{|l|}{ Employment } \\
\hline Not employed (r) & 1.00 \\
\hline Employed & 1.31 \\
\hline
\end{tabular}

Figure 2 Adjusted odds of practicing contraception, by sexual empowerment score, according to wealth quintile $(\mathrm{N}=2,104)$, Ghana, 2008

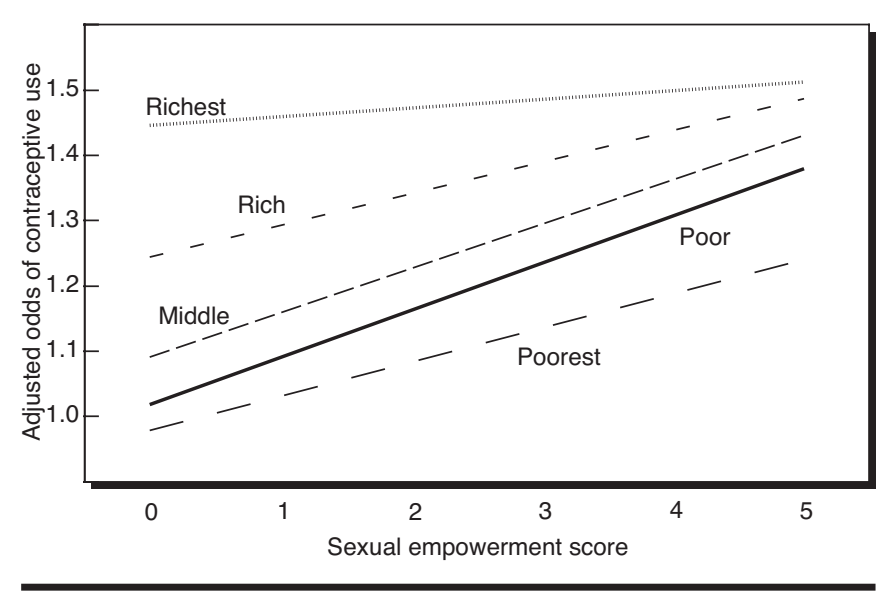

1.02; $\mathrm{p}=0.945)$, whereas individual sexual empowerment remained statistically significantly associated with contraceptive use $(\mathrm{OR}=1.24 ; \mathrm{p}<0.001)$ (not shown). 


\section{Discussion}

This analysis found that women's sexual empowerment was associated with current contraceptive use, even after adjusting for demographic characteristics. Although determining the longitudinal nature of this relationship and verifying a measure of sexual empowerment will require additional research, these findings suggest that women's sexual empowerment may play an important role in the likelihood of practicing contraception.

In the target population of married or partnered Ghanaian women aged 15-49 who were not pregnant and did not want to become pregnant in the next three months, the rate of current use of contraceptives was remarkably low; estimates indicate that less than one-third of the women used any type of method (modern, traditional, or folk). These data suggest that the unmet need for family planning in Ghana remains high (GSS 2009; Jacobstein et al. 2009).

As observed previously in Ghana (Addai 2000; Adanu et al. 2009), odds of contraceptive use did not increase incrementally with educational level (primary, secondary, or higher) (data not shown), but odds of contraceptive use were higher for those with any amount of formal education, compared with those with none. Though longitudinal data are lacking, the repeated positive association between education and contraceptive use in Ghana strongly suggests that educating girls may be an effective tool for increasing family planning and gender equity (Addai 2000; Adanu et al. 2009). Exploring more nuanced differences between women who have attended school and those who have not may also be important. Education has been linked to women's increased ability to negotiate sex in relationships; however, the persistent association of women's sexual empowerment and contraceptive use after adjusting for education suggests that formal education alone is not a proxy for sexual empowerment (Wolff, Blanc, and Gage 2000). Moreover, the association between women's sexual empowerment and contraceptive use remained strong after adjusting for employment status, which has also been used as a proxy for empowerment and was in itself not associated with contraceptive use in the current study. The use of DHS data limits the direct comparison of women's sexual empowerment to other validated measures of empowerment. Our findings suggest, however, that women's sexual empowerment is distinct from general proxies of empowerment, providing support to the theory of the multidimensional nature of empowerment.

Muslim women in the target population were estimated to have lower odds of contraceptive use, com- pared with their Christian counterparts, even after controlling for other demographic characteristics. This finding differs from previous studies in Ghana, which found no difference in contraceptive use by religious affiliation in the country's capital (Adanu et al. 2009). Ghana's Muslim population is largely concentrated in the north, far from the country's largest cities and most developed infrastructure (Gyimah, Takyi, and Tenkorang 2008). Accessing contraceptives may be significantly more difficult in the northern regions than in other rural areas, potentially resulting in religious differences in contraceptive use that may actually be attributable to geographic location. A collapsed-region variable was created to facilitate the examination of the role of region with the available sample size. As expected, the crude odds of contraceptive use in the target population was significantly higher in the South, compared with the North. The odds of contraceptive use in the North and South, however, were not significantly different in the adjusted model. In contrast, the odds of practicing contraception remained statistically significantly lower for Muslim women than Christian women in the multivariate model, suggesting that the difference in contraceptive use cannot be explained simply by accounting for differences between North and South. Future work is needed to more thoroughly disentangle the conflation of religion and region in relation to contraceptive use.

Recent work has suggested that when calculating unmet need for family planning, dichotomizing pregnancy intention into wanted and unwanted may oversimplify the issue of intention, inadequately addressing pregnancy ambivalence (Santelli et al. 2009; Schwartz et al. 2010). A plausible difference in pregnancy ambivalence between married and unmarried women may explain to some extent why married women in the target population were less likely to be practicing contraception than their unmarried, partnered counterparts. Alternatively, a number of other factors such as familial or partner pressure to produce offspring in wedlock or cultural norms regarding childbearing may be key explanatory factors for the higher rate of contraceptive use in unmarried partnerships.

Our findings suggest that even after adjusting for demographic factors associated with contraceptive use among Ghanaian partnered or married women not wanting to become pregnant, increasing sexual empowerment is associated with increasing odds of contraceptive use. The statistically significant interaction between wealth and women's sexual empowerment suggests that the association between women's sexual empowerment and contraceptive use is strongest among the poor. Logically, 
one might postulate that poorer women may need to be more sexually empowered than richer women to overcome the greater barriers to accessing contraceptives. A 2009 study in Accra by Adanu and colleagues did not find that wealth quintiles were linearly associated with contraceptive use, but postulated that within the large urban center of the capital, one's social strata may play a less significant role in mediating access to contraceptives than it does elsewhere in the country.

With notable exceptions, including Peru's ReproSalud project, which focuses specifically on empowerment as a tool to increase women's access to sexual and reproductive health services, family planning programs often avoid directly addressing empowerment as a systemic barrier to accessing services (Rogow 2000; Shrestha 2002). Many programs are modeled on the theory of reasoned action or on the health belief model, which assume that individuals are able to, and feel they have the right to, control their own behavior (Fishbein and Ajzen 1975; Rosenstock, Stretcher, and Becker 1988; Rogow 2000). The data presented here suggest that future family planning endeavors may benefit from a more critical appraisal of women's perception of their sexual rights and options. Women's sexual empowerment is embedded in social norms regarding sexuality, gender identity, and gender roles. Although the degree of gender equity varies across cultures and contexts, women are often socialized to be more passive than their male counterparts and are less likely to wield power (Blanc 2001). Given these pervasive gendered power dynamics, particularly in relation to sex, it cannot be assumed that women will be confident in their right to sexual and reproductive health and autonomy. Previous work in Ghana has revealed that the concerns of male partners regarding women's adoption of contraception often have less to do with fertility and more to do with power. Bawah and colleagues (1999) found that men feared that contraceptive use would cause them to lose control of their household or that their wives would become promiscuous. Work in other developing countries suggests that women fear violence, withdrawal of economic support, infidelity, and loss of primary partner status if discovered to be using contraceptives (Rivers et al. 1998). These findings, like those presented here, suggest that sexual empowerment in some settings may serve as a barrier to contraceptive access and, more generally, to sexual and reproductive health.

Research in Northern Ghana has indicated a significant association between spousal discussion of contraceptive use and subsequent contraceptive adoption (Bawah 2002). One might hypothesize that sexually empowered women may be better able to initiate or participate equitably in such conversations with their partners. Promoting contraceptive communication or talking to women about their rights without addressing the importance and strength of social and cultural norms, however, would likely be ineffective and potentially dangerous. Men need to be socialized out of hegemonic norms regarding exercising control over their female partners, and women need to be freed from expectations of submissiveness; both need to be allowed to develop new "scripts" for social and sexual roles (Simon and Gagnon 1987; Akeroyd 2004).

We used average regional sexual empowerment to explore the association between regional norms of sexual empowerment and contraceptive use. Though regional sexual empowerment was statistically significantly associated with contraceptive use in the univariate model, the association between regional sexual empowerment and contraceptive use lost significance in the multivariate model. More research is needed to understand the level of social aggregation (for example, community, place of worship, region) at which norms of gendered sexual disempowerment most influence individual reproductive behavior and empowerment. We suspect that the norms and expectations for sex roles and sexual empowerment that a woman is exposed to in more intimate social environments (compared with region) may play an important role in predicting both her behavior and empowerment. Although the prospect of shifting social norms is daunting, women's disempowerment need not be accepted as an intrinsic or immutable societal norm. Promoting women's empowerment has potentially strong positive implications for women's sexual and reproductive health and achievement of their fertility intentions.

Development of the sexual empowerment scale presented here was limited by the items included in the DHS. The abilities to express one's sexuality and sexual desires are examples of aspects of sexual empowerment on which the DHS does not provide data (Dixon-Mueller 1993). Use of the DHS also limited our ability to conduct a robust comparison with related empowerment scales. As such, the findings presented here are exploratory and warrant further inquiry and scale development. In addition, our model is characterized by potential for endogeneity, low homogeneity of items in the exploratory sexual-empowerment construct, and constraints associated with limited sample size. Moreover, the crosssectional nature of the data prevents us from drawing causal inferences or conclusions regarding the temporal nature of the findings. Finally, this analysis includes only women's reports. Disparities in partners' educational 
status, income, and perceptions of gender are important factors to incorporate into future analysis.

\section{Conclusion}

This study's findings suggest that greater sexual empowerment among women is associated with increased use of contraceptives, even after accounting for demographic predictors of contraceptive use. Although regional sexual empowerment was statistically significantly associated with contraceptive use in the univariate model, the association between a region's mean sexual empowerment and the contraceptive use of women living within respective regions lost significance in the multivariate model. Whereas widely recognized factors such as education and wealth were also associated with contraceptive use, assessing and addressing women's perception of their right to sexual and reproductive health and equity may be critical for the family planning community to move forward toward achieving universal access to reproductive health services.

\section{References}

Adanu, Richard M., Joseph D. Seffah, Allan G. Hill, Rudolph Darko, Rosemary B. Duda, and John K. Anarfi. 2009. “Contraceptive use by women in Accra, Ghana: Results from the 2003 Accra women's health survey," African Journal of Reproductive Health 13(1): 123-133.

Addai, Isaac. 2000. "Determinants of use of maternal-child health services in rural Ghana," Journal of Biosocial Science 32: 1-15.

Adongo, Philip B., James F. Phillips, Beverly Kajihara, Clara Fayorsey, Cornelius Debpuur, and Fred N. Binka, 1997. "Cultural factors constraining the introduction of family planning among the KassenaNankana of northern Ghana," Social Science and Medicine 45(12): 1789-1804.

Akeroyd, Anne V. 2004. "Coercion, constraints, and 'cultural entrapments': A further look at gendered and occupational factors pertinent to the transmission of HIV in Africa," in Ezekiel Kalipeni, Susan Craddock, Joseph R. Oppong, Javati Ghosh (eds.), AIDS in Africa, Beyond Epidemiology. Malden, MA: Blackwell Publishing Ltd., pp. 89-103.

Amaro, Hortensia. 1995. "Love, sex, and power: Considering women's realities in HIV prevention," American Psychologist 50(6): 437-447.

Anate, M. 1995. "Factors influencing family planning in Ilorin, Nigeria," East African Medical Journal 72(7): 418-420.

Bandura, Albert. 1990. "Perceived self-efficacy in the exercise of control over AIDS infection," Evaluation and Program Planning 13: 9-17.

Basen-Engquist, Karen. 1992. "Psychosocial predictors of "safer-sex" behaviors in young adults," AIDS Education and Prevention 4(2): 120-134.
Bawah, Ayaga A. 2002. "Spousal communication and family planning behavior in Navrongo: A longitudinal assessment," Studies in Family Planning 33(2): 185-194.

Bawah, Ayaga A., Patricia Akweongo, Ruth Simmons, and James F. Phillips. 1999. “Women's fears and men's anxieties: The impact of family planning on gender relations in northern Ghana," Studies in Family Planning 30(1): 54-66.

Binder, David A. 1983. “On the variances of asymptotically normal estimators from complex surveys," International Statistical Review 51: $279-292$

Blanc, Ann K. 2001. "The effect of power in sexual relationships on sexual and reproductive health: An examination of the evidence," Studies in Family Planning 32(3): 189-213.

Blanc, Ann K. and Amy O. Tsui. 2005. "The dilemma of past success: Insiders' views of the future of the international family planning movement," Studies in Family Planning 36(4): 263-276.

Blanc, Ann K. and Brent Wolff. 2001. "Gender and decision-making over condom use in two districts of Uganda," African Journal of Reproductive Health 5(3): 15-28.

Bowleg, Lisa, Faye Z. Belgrave, and Carol A. Reisen. 2000. “Gender roles, power strategies, and precautionary sexual self-efficacy: Implications for black and Latina women's HIV / AIDS protective behaviors," Sex Roles 42(7/8): 613-635.

Cabral, Rebecca J., LeaVonne Pulley, Lynn M. Artz, Ilene Brill, and Maurizio Macaluso. 1997. "Women at risk of HIV/STD: The importance of male partners as barriers to condom use," AIDS and Behavior 2(1): 75-85.

Cochran, Susan D. and Vickie M. Mays. 1993. “Applying social psychological models to predicting HIV-related sexual risk behaviors among African Americans," Journal of Black Psychology 19(2): 142-154

Cochran, Susan Hill. 1979. Education and Fertility: What Do We Really Know? Baltimore: Johns Hopkins University Press.

Dixon-Mueller, Ruth. 1993. "The sexuality connection in reproductive health," Studies in Family Planning 24(5): 269-282.

Fishbein, Martin and Icek Ajzen (eds.). 1975. Belief, Attitude, Intention, and Behavior: An Introduction to Theory and Research. Reading, MA: Addison-Wesley.

Gage, Anastasia J. 1995. "Women's socioeconomic position and contraceptive behavior in Togo," Studies in Family Planning 26(5): 264-277.

Ghana Statistical Service (GSS), Ghana Health Service, and ICF Macro. 2009. Ghana Demographic and Health Survey 2008. Accra: GSS, GHS, and ICF Macro. <http://.pdf.usaid.gov/pdf_docs/PNADQ630. pdf $>$. Accessed 23 April 2012.

Grieg, Fiona E. and Cheryl Koopman. 2003. "Multilevel analysis of women's empowerment and HIV prevention: Quantitative survey results from a preliminary study in Botswana," AIDS Behavior 7(2): 195-208

Gutiérrez, Lorraine, Hyun Joo Oh, and Mary Rogers Gillmore. 2000. "Toward understanding of (em)power(ment) for HIV / AIDS prevention with adolescent women," Sex Roles 42(7/8): 581-611.

Gyimah, Stephen O., Baffour Takyi, and Eric Y. Tenkorang. 2008. “Denominational affiliation and fertility behavior in an African context: An examination of couple data from Ghana," Journal of Biosocial Science 40: 445-458. 
Harvey, S. Marie, Sheryl T. Bird, Christine Galavotti, Ernestine A. Duncan, Donna Greenberg. 2002. "Relationship power, sexual decision making and condom use among women at risk for HIV/STDs," Women \& Health 36(4): 69-84.

Heeringa, Steven G., Brady T. West, Patricia A. Berglund. 2010. Applied Survey Data Analysis, 1st Edition. Boca Raton: Taylor \& Francis.

Heinrich, Linda B. 1993. "Contraceptive self-efficacy in college women," Journal of Adolescent Health 14(4): 269-276.

Hosmer, David W. and Stanley Lemeshow. 2000. Applied Logistic Regression, 2nd Edition. New York: Wiley.

Jacobstein, Roy, Lynn Bakamjian, John M. Pile, and Jane Wickstrom. 2009. "Fragile, threatened, and still urgently needed: Family planning programs in sub-Saharan Africa," Studies in Family Planning 40(2): 147-154.

Kannae, Lawrence and Brian F. Pendleton. 1998. "Socioeconomic status and use of family planning among Ghanaian government workers," Social Biology 45(1-2): 113-133.

Khan, Mehrab A. 1996. "Factors affecting use of contraception in Matlab, Bangladesh," Journal of Biosocial Sciences 28(3): 265-279.

Kim, Julia, Paul Pronyk, Tony Barnett, Charlotte Watts. 2008. “Exploring the role of economic empowerment in HIV prevention," AIDS 22(Suppl. 4): S57-S71.

Lee-Rife, Susan M. 2010. “Women's empowerment and reproductive experiences over the lifecourse," Social Science and Medicine 71: 634-642.

Levinson, Ruth A. 1986. "Contraceptive self-efficacy: A perspective on teenage girls' contraceptive behavior," Journal of Sex Research 22(3): 347-369.

Malhotra, Anju and Rekha Mehra. 1999. “Fulfilling the Cairo commitment: Enhancing women's economic and social options for better reproductive health." Washington, DC: International Center for Research on Women.

Malhotra, Anju, Sidney R. Schuler, and Carol Boender. 2002. "Measuring women's empowerment as a variable in international development." Washington, DC: Gender and Development Group, World Bank. <http:/ / siteresources.worldbank.org/INTGENDER/ Resources/MalhotraSchulerBoender.pdf $>$. Accessed 24 April 2012.

Mason, Karen O. 1984. The Status of Women: A Review of its Relationship to Fertility and Morality. New York: Rockefeller Foundation.

Njogu, Wamucii. 1991. "Trends and determinants of contraceptive use in Kenya," Demography 28(1): 83-99.

Orji, Ernest O. and Uche Onwudiegwu. 2002. "Prevalence and determinants of contraceptive practice in a defined Nigerian population," Journal of Obstetrics and Gynecology 22(5): 540-543.

Pearson, Jennifer. 2006. "Personal control, self-efficacy in sexual negotiation, and contraceptive risk among adolescents: The role of gender," Sex Roles 54: 615-625.

Pettifor, Audrey E., Diana M. Measham, Helen V. Rees, Nancy S. Padian. 2004. "Sexual power and HIV risk, South Africa," Emerging Infectious Diseases 10(11): 1996-2004.

Pulerwitz, Julie, Hortensia Amaro, Wouter DeJong, Steven L. Gortmaker, Rima Rudd. 2002. "Relationship power, condom use and HIV risk among women in the USA," AIDS Care 14: 789-800.
Pulerwitz, Julie, Steven L. Gortmaker, Wouter DeJong. 2000. “Measuring sexual relationship power in HIV/STD research," Sex Roles 42(7/8): 637-658

Rivers, Kim, Peter Aggleton, Jorge Elizondo, et al. 1998. "Gender relations, sexual communication and the female condom," Critical Public Health 8(4): 273-290.

Rogow, Debbie. 2000. "Alone you are nobody, together we float: The Manuela Ramos movement." New York: Population Council. $<$ http://www.popcouncil.org/pdfs/qcq/qcq10.pdf >. Accessed 24 April 2012.

Rosenstock, Irwin M., Victor J. Stretcher, and Marshall H. Becker. 1988. "The health belief model," in Karen Glanz, Barbara K. Rimer, and Frances M. Lewis (eds.), Health Behavior and Health Education: Theory, Research and Practice, 2nd Edition. San Francisco: JosseyBass, pp. 31-44.

Rosenthal, Doreen, Susan Moore, and Irene Flynn. 1991. "Adolescent self-efficacy, self-esteem and sexual risk-taking," Journal of Community and Applied Social Psychology 1: 77-88.

Santelli, John S., Laura Duberstein Lindberg, Mark G. Orr, Lawrence B. Finer, and Ilene Speizer. 2009. "Toward a multidimensional measure of pregnancy intentions: Evidence from the United States," Studies in Family Planning 40(2): 87-100.

Schwartz, Alan, Nadine Peacock, Kenya McRae, Rachel Seymour, and Melissa Gilliam. 2010. "Defining new categories of pregnancy intention in African-American women," Women's Health Issues 26(6): 371-379.

Shrestha, Sarala. 2002. "Increasing contraceptive acceptance through empowerment of female community health volunteers in rural Nepal," Journal of Health, Population and Nutrition 20(2): 156-165.

Sikkema, Kathleen J., Jeffrey J. Koob, Victoria C. Cargill, et al. 1995. “Levels and predictors of HIV risk behavior among women in low-income public housing developments," Public Health Reports 110(6): 707-713.

Simon, William and John H. Gagnon. 1987. "Sexual scripts," in James H. Geer and William T. O'Donohue (eds.), Theories of Human Sexuality. London: Plenum Press, pp. 363-383.

Sionéan, Catlainn and Rick S. Zimmerman. 1999. “Moderating and mediating effects of socioeconomic status, perceived peer condom use and condom negotiation on sexual risk behavior among African American and white adolescents," Annals of the New York Academy of Sciences 896: 474-476.

Soler, Hosanna, David Quadagno, David F. Sly, Kara S. Richman, Isaac W. Eberstein, and Dianne F. Harrison. 2000. "Relationship dynamics, ethnicity, and condom use among low-income women," Family Planning Perspectives 32(2): 82-88, 101.

Swart-Kruger, Jill and Linda M. Richter. 1997. “AIDS-related knowledge, attitudes and behavior among South African street youth: Reflections on power, sexuality and the autonomous self," Social Science \& Medicine 45(6): 957-966.

Teitelman, Anne M., Sarah J. Ratcliffe, Mercedes M. Morales-Aleman, Cris M. Sullivan. 2008. "Sexual relationship power, intimate partner violence, and condom use among minority urban girls," Journal of Interpersonal Violence 23(2): 1694-1712.

Wang, Ruey-Hsia and Chii-Jun Chiou. 2008. "Relative contribution of intrapersonal and partner factors to contraceptive behavior among Taiwanese female adolescents," Journal of Nursing Scholarship 40(2): 131-136. 
Williams, Jill. 2005. "Measuring gender and women's empowerment using confirmatory factor analysis." Working paper, Research Program on Population Processes, Institute of Behavioral Sciences, University of Colorado at Boulder. <http: / www.colorado.edu/ $\mathrm{ibs}$ / pubs/ pop/ pop2005-0001.pdf > . Accessed 24 April 2012.

Wolff, Brent, Ann K. Blanc, Anastasia J. Gage. 2000. “Who decides? Women's status and negotiation of sex in Uganda," Culture, Health $\mathcal{E}$ Sexuality 2(3): 303-322.

\section{Acknowledgments}

The authors are indebted to Ghana Statistical Services and Ghana Health Services for use of Ghana Demographic Health Survey data. We would also like to thank Brady T. West at the University of Michigan, Center for Statistical Consultation and Research, for software assistance and statistical consultations. 